\title{
Contratação de docentes na EJA \\ no município do Rio de Janeiro
}

\section{Faculty hiring in EJA}

In the municipality of Rio de Janeiro

\section{Contratación de docentes en la EJA}

en el municipio de Rio de Janeiro

\section{CARLA DA MOTA SOUZA*}

Universidade Federal Fluminense, Niterói- RJ. Brasil.

\begin{abstract}
RESUMO: O artigo apoia-se na tese de doutorado realizada pela autora no município do Rio de Janeiro entre 2014-2018. Objetiva analisar a política educacional de contratação dos docentes da educação de jovens e adultos (EJA), mediante ao perfil de seleção. Pesquisa qualitativa; método do materialismo histórico-dialético e análises conceituais de Bourdieu: habitus, campo, agente e capital cultural. O perfil de professor doe EJA torna-se uma retórica vazia enquanto requisito seletivo, uma vez que a identidade/perfil do professor se estabelece em processo contínuo de construção. Sugestão do campo: concurso público como melhor política de contratação.
\end{abstract}

Palauras-chave: Educação de Jovens e Adultos. Contratação docente. Perfil docente.

\begin{abstract}
The article is based on the doctoral research carried out by the author in the municipality of Rio de Janeiro between 20142018. It aims to analyze the hiring process of the educational faculty for the Young and Adult Education (EJA), through profile selection. Qualitative research; method of historical-dialectical materialism and conceptual analysis of Bourdieu: habitus, field, agent and cultural
\end{abstract}

* Doutora em Educação pela Universidade Federal do Rio de Janeiro, Docente da Rede Municipal do Rio de Janeiro. Professora de educação Fundamental e do Peja, com foco em Alfabetização. E-mail: $<$ carllamotta@hotmail.com>. 
capital. The teacher profile of EJA becomes an empty rhetoric as a selection requirement, since the identity / profile of the teacher is in continuous process of construction. Suggestion of the field: public selection as best hiring policy.

Keywords: Young and Adult Education. Faculty hiring. Faculty profile.

RESUMEN: El artículo se basa en la tesis doctoral realizada por la autora en la ciudad del Río de Janeiro entre 2014-2018. Su objetivo es analizar la política educativa de contratación de docentes de educación de jóvenes y adultos (EJA), a través del perfil de selección. Se trata de investigación cualitativa; método del materialismo histórico-dialéctico y análisis conceptual de Bourdieu: habitus, campo, agente y capital cultural. El perfil del profesor de EJA se convierte en una retórica vacía como un requisito selectivo, ya que la identidad/perfil del profesor se establece en un proceso continuo de construcción. Sugestión del campo: concurso público como la mejor política de contratación.

Palabras clave: Educación de Jóvenes y Adultos. Contratación docente. Perfil docente.

\section{Introdução}

$\mathrm{E}$ stamos no Brasil, no século XXI, e há um a luta contínua para que os professores tenham formação adequada e valorização no exercício de sua profissão. Embora seja de consenso nacional que quanto melhor a formação do docente e sua valorização, melhor será a educação, ainda são latentes os paradigmas a serem quebrados para que de fato ocorra uma mudança de tratamento a esses profissionais.

A Lei $\mathrm{n}^{\circ} 11.738$ de 16 de julho de 2008 foi sancionada e instituiu o piso salarial nacional para os profissionais do magistério público da educação básica. Entre as bases estabelecidas, a Lei também regulou o direito de 1/3 da carga horária para atividades extraclasse. Embora já tivesse a disposição prevista na Constituição Federal (1988) (alínea 'e' do inciso III do caput do artigo 60 do Ato das Disposições Constitucionais Transitórias) e na Lei de Diretrizes e Base da Educação (LDB/Lei nº 9.394/96). Todos esses dispositivos legais não têm sido suficientes para garantir a exequibilidade, portanto, há necessidade de se fazer o enfrentamento em todos os cenários educacionais.

O desprestígio dos professores é real e quando se trata dos docentes da educação de jovens e adultos (EJA), o descrédito é maior, seja por alunos, quanto por professores de outras modalidades de ensino, somando-se a grande parte da sociedade, que tem 
uma visão estereotipada da própria EJA e, por conseguinte, destes docentes, como lembra Brutti et al.:

\begin{abstract}
a Educação para Jovens e Adultos é vista com uma espécie de preconceito tanto por educadores, alunos como também pela comunidade em geral. Não raro a visão que se tem desta modalidade de ensino é que a EJA surgiu para complementar uma instrução deficitária, servindo somente para ensinar a ler e escrever adultos e adolescentes, estes últimos geralmente tidos como "alunos problemas". Por isso, a formação do professor que atua nesta área é, por vezes, tida sob uma ótica de menor importância (2014.p. 8).
\end{abstract}

Essa visão é reafirmada no imaginário das pessoas, pois o despreparo dos docentes é fato estudado em vários municípios brasileiros, conforme trabalhos publicados de Capucho (2012), Laffin e Gaya (2013), entre outros. Mediante esse descompasso formativo e, por conseguinte, (des)valorativo, torna-se imperioso analisar como se configuram as políticas de seleção dos professores na EJA-RJ, uma vez que não existe concurso público para essa modalidade no município.

Assim, o objetivo deste artigo foi analisar a política educacional de contratação dos docentes do Programa de Educação de Jovens e Adultos (PEJA), do município do Rio de Janeiro, problematizando o perfil dos professores selecionados para atuarem na modalidade.

A pesquisa se justifica, porque o assunto é praticamente invisível no cenário educacional do município, urgindo por se constituir de assunto relevante na pauta de políticas públicas da Secretaria Municipal de Educação, porque a contratação, formação e valorização dos professores que atuam na EJA é diretamente proporcional à melhoria da educação dos alunos desta modalidade.

\title{
Metodologia
}

Os pilares deste artigo são derivados de pesquisa de doutorado realizada nas 11 (onze) Coordenadorias Regionais de Educação (CRE) do município do Rio de Janeiro, no período entre 2014-2018. Foi realizado um recorte da pesquisa sobre a política de seleção dos professores do PEJA, utilizando às analises as vozes dos 14 agentes entrevistados. Onze professores acompanhantes de PEJA, que são elos entre as escolas e o programa, as CRE e a Gerência de Educação de Jovens e Adultos (GEJA), e, também, dos três professores que compõem a própria GEJA, que são responsáveis majoritariamente pelo funcionamento e diretrizes do PEJA.

Para embasar este trabalho, foram analisados os extratos das entrevistas de forma dialética e à luz de quatro conceitos de Bourdieu. O primeiro: Habituso, conceito que permite compreender a oposição aparente entre realidade exterior e as realidades individuais dentro de conjunturas inerentes a um determinado campo. 
[...] um sistema de disposições duráveis e transponíveis que, integrando todas as experiências passadas, funciona a cada momento como uma matriz de percepções, de apreciações e de ações - e torna possível a realização de tarefas infinitamente diferenciadas, graças às transferências analógicas de esquemas [...] (BOURDIEU, 1983b, p. 65).

O segundo: Campo, conforme Bourdieu, a sociedade é composta por vários campos, vários espaços dotados de relativa autonomia, mas regidos por regras próprias.

[...] a existência de um campo especializado e relativamente autônomo é correlativa à existência de alvos que estão em jogo e de interesses específicos: através dos investimentos indissoluvelmente econômicos e psicológicos que eles suscitam entre os agentes dotados de um determinado habitus, o campo e aquilo que está em jogo nele produzem investimentos de tempo, de dinheiro, de trabalho etc. [...] Todo campo, enquanto produto histórico, gera o interesse, que é condição de seu funcionamento. (BOURDIEU, 1990, p. 126-128). (grifo do autor).

O terceiro: Agente, para Bourdieu (1990), a maior parte das ações dos agentes sociais é produto de um encontro entre um habitus e um campo (conjuntura). Reconhecer esses agentes, o campo que trabalham, as condições postas entre os que gerenciam e os que obedecem, a macro-estrutura que é a SME- RJ, fez parte das análises das entrevistas.

O quarto: Capital Cultural, segundo Bourdieu (1979, p. 88-93), o capital cultural são caracteres corporificados, que tornam-se parte integrante da pessoa: um habitus, uma combinação de propriedades variadas, e um certo ethos, ou seja, um sistema de valores implícitos e profundamente interiorizados, que contribui para definir, entre outras coisas, as atitudes face ao capital cultural e à instituição escolar.

A pesquisa foi qualitativa, porque o conhecimento é uma construção coletiva, portanto, parte da realidade dos sujeitos, mediados por processos de reflexão e desvelamento da realidade estudada, conforme esclareceu Richardson:

[..] O objetivo fundamental da pesquisa qualitativa não reside na produção de opiniões representativas e objetivamente mensuráveis de um grupo; está no aprofundamento da compreensão de um fenômeno social por meio de entrevistas em profundidade e análises qualitativas da consciência articulada dos atores envolvidos no fenômeno (1999, p. 102).

Neste estudo, o método fundante foi o Materialismo Histórico-Dialético, que parte do conceito basal de que o mundo não pode ser considerado um complexo de coisas acabadas, mas, sim, um processo de complexos, (SANFELICE, 2008). Assim, o grande desafio é buscar a essência do fenômeno, aquilo que está por detrás da aparência, ou seja, o caráter conflitivo, dinâmico e histórico da realidade. Desta maneira:

[...]ao final do processo de investigação, o resultado não será mais as representações iniciais do dado empírico, mas o fato social em si concretamente pensado. Esta apropriação teórica não tem como se dar sem a mediação do conhecimento da realidade histórica até mesmo porque a apreensão do caráter histórico do fenômeno 
traz consigo toda relatividade, parcialidade e provisoriedade do conhecimento histórico-social (FRIGOTTO, 1991, p. 7).

Desta forma, para se combater as injustiças e promover a equidade social é necessário, primeiramente, conhecer a história do PEJA, sua estrutura, seus alunos, assim como a contratação dos docentes e sua identidade.

\section{Desenvolvimento}

Nessa sessão foi utilizada a estrutura expositiva de Fávero (2004), para recontar os fatos históricos, com acréscimos, comentários e supressões, feitas pela pesquisadora. A história do PEJA inicia-se no ano de 1984 no município do Rio de Janeiro, portanto, são trinta e cinco anos de Projeto, em vigor até o presente ano de 2019.

Inicialmente, era um projeto de educação alternativa para adolescentes, atendendo a jovens da alfabetização a $4^{\text {a }}$ série antiga, atual $5^{\circ}$ ano do ensino fundamental (EF). A proposta metodológica era baseada em aulas de técnicas comerciais, Inglês, Artes Industriais, Artes Plásticas, Educação para o Lar e Educação Musical. Esta proposta foi encampada pelo Projeto de Educação Juvenil, que surge no ano 1985. Portanto, o ano de 1985 é considerado pela maioria dos autores como marco deste Programa, devido à sua maior amplitude.

OPEJA, como se conhece hoje, não tinha essa designação em sua origem. Ele se chamava Programa de Educação Juvenil (PEJ) e fazia parte como elemento constituinte de um outro e maior programa, conhecido como Programa Especial de Educação (PEE), que fora elaborado por Darcy Ribeiro, professor e também vice-governador, junto com Leonel Brizola, em seu primeiro mandato no estado do Rio de Janeiro (1982-1986). Iniciou-se com 20 Centros Integrados de Educação Pública (Ciep).

O PEJ foi idealizado para atender à população analfabeta de 15 a 20 anos. A proposta pedagógica era baseada na "perspectiva cidadã" e na concepção de Paulo Freire. Para efeitos didáticos, passa-se a dividir o percurso histórico em quatro etapas distintas.

\section{Primeira etapa (1984-1991)}

Criação do Programa e implantação aligeirada; crise e sobrevivência em algumas escolas, pois o empenho era sofrível dos poucos professores "convidados" a integrar o Programa, e havia baixa frequência dos alunos de quinze a vinte anos. Entretanto, seu mentor, Darcy Ribeiro, compreendia que se justificava, porque eram jovens marginalizados ao mercado de trabalho devido ao seu despreparo educacional, podendo cometer 
irregularidades sociais. (RIO DE JANEIRO, 1985, p. 29). A organização curricular abrangia as seguintes áreas: Linguagem, Matemática, Realidade Social e Cidadania, Saúde, Educação Física, Arte e Cultura, todas conexas à alfabetização.

A proposta original pretendia abarcar no máximo vinte turmas por Ciep e com quinze alunos para cada uma delas. A carga horária era de quatro horas e se dividia da seguinte maneira: 18h às 19h, jantar; 19h às 21h, aula; 21h às 22h, Educação Física ou Artes. Em 1987, em resposta à reivindicação dos alunos e professores, o Programa foi ampliado, passando a atender alunos que queriam dar prosseguimento aos estudos e outros que já tinham maior escolaridade e queriam voltar a estudar (FÁVERO; BRENNER/2006).

A organização então passou a dar-se em dois blocos de aprendizagem: alfabetização inicial e o segundo bloco, com a consolidação da alfabetização e conteúdos referentes aos cinco anos, do atual ciclo da educação fundamental. Neste primeiro momento não se podia certificar oficialmente o curso, pois ele não era reconhecido pelos conselhos estadual ou municipal de educação. Somente em 1999 obteve-se a licença legal. Normalmente os alunos eram transferidos para o ensino supletivo (ES) diurno. Coexistia, portanto, o PEJ no município e o ES no estado.

\section{Segunda etapa (1992-1996)}

A partir de 1992 a infraestrutura do Programa passou a ser modificada devido à falta de investimentos. Dias (1995) assegura que a partir de 1990 as atividades de Educação Artística e de Educação Física deixaram de ser ministradas pelos professores do PEJ, passando a ser efetivadas pelos professores da escola regular diurna, que complementavam suas cargas horárias. Eles não tinham formação e compromisso com a ideologia do Programa. Assim, com o decorrer dos anos, essas atividades deixaram de existir. $\mathrm{Na}$ época houve muitas críticas ao funcionamento do Programa, pois, a estrutura dos Centros Integrados de Educação Públicas (CIEP) eram vistas como majestosas e eleitoreira. (FÁVERO; BRENNER, 2006).

Com a Lei n 5.692/71 vigorando, houve uma "debandada" dos alunos de quatorze anos com defasagem série/idade e dos mais idosos das escolas diurnas para os supletivos ou para o regular noturno. Percebe-se que a proposta original perdia seus fundamentos e houve um enxugamento do ensino regular. Segundo Benício (2006), nesse momento passa a haver um descompasso, pois nem todos os professores seguiam a proposta original e, desta forma, alguns passaram a adotar a seriação e a avaliação regular.

Com mudanças de governantes: Moreira Franco no governo e César Maia na prefeitura (1992-1996), ocorre a modificação radical do Projeto do estado e município. A Secretaria Municipal de Educação (SME/RJ) passou a privilegiar a Educação Infantil e o PEJA encolheu, passando a ser um projeto do setor de Programas Sociais. Para se ter uma 
ideia da redução de CIEPS, no ano de 1995 somente quinze deles continuaram a funcionar. Sem apoio da SME/RJ, o Programa minguou, restando algumas unidades escolares de resistência. Mas Moreira Franco encerrou o PEE, ficand o o Programa à deriva. Professores e alunos resistiam ao descompromisso do governo.

\section{Terceira etapa (1996 até 2009)}

Surge então um convênio entre a SME/RJ e o MEC, no ano de 1996, que passou a destinar recursos do FNDE à EJA no município. Na época foi realizado o I Encontro de Jovens $e$ Adultos. Esse encontro teve um papel fundamental no fortalecimento do Programa, pois teve a participação de docentes da rede pública e de instituições não-governamentais que, após reflexões, construíram uma proposta de ação. No ano seguinte, 1997, aconteceu o II Encontro de Jovens e Adultos, que reestruturou e normatizou o Programa educacional da SME/RJ. A proposta enviada ao MEC tinha o objetivo de aumentar o número de turmas e contava com a seguinte estruturação: PEJA I (correspondia ao atual ciclo $1^{\circ}$ a $5^{\circ}$ ano do EF). Pretendia passar de 64 para 130 turmas e aumentar o número de alunos de 3.200 para 5000. Na sequência, criava o PEJA II (correspondia ao atual ciclo 5o ao 9o do $\mathrm{EF}$, nos anos de 1998 e 1999). Esse convênio seria a âncora financeira para capacitação dos profissionais do PEJA. A nova estruturação passava a privilegiar o ensino não-seriado, acelerado e progressivo, realizado de forma presencial, em horário noturno, distinto do ensino supletivo e do regular noturno (FÁVERO; BRENNER; 2006).

O número de alunos deveria ser 25 no máximo e cem alunos por escola. A organização em dois segmentos: PEJA I, correspondendo ao $1^{\circ}$ segmento do EF, e PEJA II, correspondendo ao $2^{\underline{ }}$ segmento. Cada segmento se desdobraria em dois blocos; PEJA I atenderia jovens de 14 a 22 anos iniciados no Bloco 1 que, após cursarem tal bloco obtendo uma avaliação positiva, passariam ao Bloco 2. Assim, sucessivamente, até chegar ao PEJA II, que atenderia jovens de 14 a 25 anos, que não concluíram o EF, também dividido em dois blocos, com 870 horas cada, cabendo a cada componente curricular sessenta horas em cada unidade de progressão, perfazendo 180 horas no bloco.

Em 2003, o atendimento diurno é ampliado, pois muitos alunos trabalhavam no horário noturno e, assim, conseguiam estudar em horário apropriado à sua vida profissional. Em 2004, após o convênio com a Secretaria Municipal de Assistência Social, foram abertas 156 Classes Anexas, compondo o Programa Aumento de Escolaridade (PAE). Essas classes estavam localizadas em diferentes comunidades, todas atendidas pelo Programa Favela Bairro. Foram implantadas em diferentes áreas da cidade e funcionavam com turmas do PEJA no turno da manhã e da tarde a fim de ampliar o acesso escolar ainda mais. 
Ainda em 2004 foi criado o Centro de Referência de Educação de Jovens e Adultos (Creja), localizado no centro comercial da cidade, objetivando atender um maior contingente de trabalhadores da área central. Finalmente, o PEJ, como era conhecido, foi modificado para PEJA, em 2005, por meio do Conselho Municipal de Educação, através do parecer 06/2005.

\section{Quarta etapa (2010 até a atualidade)}

A quarta fase traz como marco a educação à distância (EAD), modalidade de ensino até aqui inexistente na EJA. Foi com a Resolução № 3, de 15 de junho de 2010, que se instituíram as Diretrizes Operacionais para a Educação de Jovens e Adultos nos aspectos: duração dos cursos; idade mínima para ingresso nos cursos de EJA; idade mínima e certificação nos exames de EJA; e educação de jovens e adultos desenvolvida por meio da educação a distância.

O PEJA funciona atualmente em 133 escolas espalhadas nas onze CREs do município do Rio de Janeiro. Desde a criação em 1984/1985, até os dias atuais, a contratação dos professores é feita por requisição, prerrogativa concedida aos diretores de escolas com o PEJA, que, mediante ajuizamento próprio, selecionam os professores já concursados pela Rede Municipal de outras modalidades a virem fazer parte do corpo docente do PEJA. O que circula no campo escolar é que os docentes são selecionados mediante um "perfil" específico, condicionado aos requisitos necessários para lidar com os alunos do PEJA. Embora não se encontrem documentos legais que definam tal "perfil".

\section{Análise da política de contratação do perfil dos docentes}

Nessa sessão foram trazidos alguns extratos das entrevistas dos agentes da pesquisa de referência, para serem analisadas dialeticamente.

Sabe-se que na atualidade a contratação dos professores do PEJA ocorre via requisição, ou seja, são os diretores de escolas de PEJA que escolhem os professores que vão fazer parte da equipe da sua escola. Essa requisição é baseada no discurso de que tais professores selecionados têm o "perfil" desejado para atuar no Programa.

Embora esse processo de contratação seja majoritário, vêm ocorrendo alterações, respaldadas pela SME-RJ. São adaptações circunstanciais, para atender a professores recém-concursados, com carga horária de 40h, que já tinham uma outra matrícula, necessitando ser conduzidos para o PEJA sem a interferência dos diretores de escolas do PEJA.

Mediante esse cenário, retirou-se da pesquisa a seguinte pergunta feita aos professores acompanhantes de PEJA: estudos apontam para uma má formação profissional dos 
docentes do PEJA, desta forma, o concurso público pode ser uma boa política de contratação para ingresso dos docentes do PEJA? Ou a política atual de requisição é a mais adequada? Seguem alguns extratos de respostas:

"não concordo, pois iria fugir a estrutura do Programa".

"mais encontros com trocas de experiências e licença para fazermos cursos de pós-graduação na nossa área. Quanto ao concurso...não sei responder, a proposta atual ficaria descaracterizada, mas por outro lado já estamos descaracterizando com a entrada de professores $40 \mathrm{~h}$ em concursos e acomodações funcionais...Talvez..."

"Acho que o concurso não iria ser a solução. (pausa para pensar), apesar de que hoje em dia não se recorre mais aos bancos de inscrições, o diretor que indica e também agora temos a questão dos professores de 40 h que estão chegando, então não sei.... por outro lado poderia legitimar e também normatizar a EJA, porque os professores vivem com medo de acabar essa modalidade. Qualquer coisa, se fala em fechar turmas e o professor tem medo de ficar sem aquela unidade de trabalho".

"Creio que o concurso fosse moralizar a entrada de professores, que por muitas vezes pensam em ir para o PEJA para se livrar dos gritos das crianças, das correções de provas e assim, trabalharem menos".

“Gostaria que a formação dos professores fosse mais frequente e que a GED tivesse uma pessoa responsável só para isso. Que as práticas dos professores fossem mais valorizadas entre si. Creio que o concurso fosse moralizar a entrada de professores, que por muitas vezes pensam em ir para o PEJA para se livrar dos gritos das crianças, das correções de provas e assim trabalhar menos."

“Quanto ao concurso...não sei responder, a proposta atual ficaria descaracterizada, mas por outro lado já estamos descaracterizando com a entrada de professores $40 \mathrm{~h}$ em concursos e acomodações funcionais...Talvez fosse bom, o concurso, não sei responder" (MOTA SOUZA, 2018, p. 225).

As análises feitas, conforme os pilares conceituais de Bourdieu, desvelam a proposta vigente como tendenciosa, porque ao diretor é dado o poder decisório da requisição dos professores do PEJA, portanto, ele pode privilegiar os seus amigos, já que o trabalho no PEJA é considerado pelos próprios entrevistados como mais tranquilo, sem gritos de crianças, com maior flexibilidade no horário de entrada e saída.

Quando a mesma pergunta foi feita aos gestores da GEJA, eles disseram que esse critério é de fato subjetivo e que na realidade não existem características (perfil) pré-estabelecidas em lei, mas que deveriam gostar de trabalhar com jovens e adultos e compreender as necessidades destes alunos, que trazem histórias de negações em seu trajeto de vida. Ainda disseram que deveriam ser professores atualizados, dinâmicos, dispostos a dialogar e disponíveis.

Os respondentes da GEJA também disseram que esperavam que os diretores fossem criteriosos, mas que sabem que existem professores sem o compromisso necessário, assim como diretores que contemplam profissionais amigos. Duas pessoas da equipe disseram que o concurso deve ser pensado como proposta de seleção e outra disse que não, 
explicou que, pelo fato das universidades não formarem professores para essa modalidade, achavam melhor continuar com o critério da requisição por indicação. Embora já se saiba que muitas universidades já se adequaram em seu quadro disciplinar, oferecendo cadeiras obrigatórias para a EJA, essa adequação ainda urge por se firmar em todas as IES.

Trago Soares (2007) à discussão, reafirmando a concepção da necessidade de se oficializar concurso público à modalidade da EJA, pois ela estabelece mais qualificação dos professores. O município do Rio de Janeiro já pratica uma política de contratação dirigida para cada modalidade de ensino, via concurso público. Existem as professoras específicas para lidar com a educação infantil, denominadas PEI e também as professoras, para lidar com o ensino fundamental dos anos iniciais e finais, as chamadas PEF, mas ainda não foi criado um concurso que seja exclusivo à área do PEJA. A autora cita o concurso público como política de enfrentamento à melhoria do ensino ofertada aos alunos da EJA. Diz ela:

[...] entre os desafios a serem enfrentados na formulação de políticas públicas encontra-se a profissionalização dos educadores. A falta de concurso público direcionado à EJA contribui para que o campo reproduza o amadorismo e o improviso no enfrentamento de suas questões (SOARES, 2007, p.315).

Neste sentido, a proposta é relevante e tem subsídios para ser empregada, faltando vontade política e amadurecimento da GEJA junto ao órgão competente da SME- RJ.

Dialogando com Diniz (2018) sobre o perfil dos docentes, percebe-se o posicionamento claro do autor, que, entre outras palavras, esclarece que o perfil ou identidade do professor se constrói trabalhando, no dia-a-dia dos problemas que surgem e nas maneiras pelas quais são resolvidas. O professor reflexivo, avalia a todo instante suas práticas, porque ele é pesquisador do seu fazer pedagógico.

Nóvoa (1992) é outro autor que explica que "“"a formação não se constrói por acumulação (de cursos, de conhecimentos ou de técnicas) mas, sim, através de um trabalho de flexibilidade crítica sobre as práticas e de (re)construção permanente de uma identidade pessoal." O que Nóvoa (1992) chama de "acúmulo", Bourdieu chamaria de "experiências capitalizadas", assim, recorre-se a Bourdieu com seu conceito de capital e ratifica-se que todos os cursos, encontros, palestras, passeios e demais interações se incorporam ao capital cultural dos agentes, que, por meio do habitus, se relacionam à capacidade oferecida pela estrutura social, no caso da GEJA/SME, por meio de disposições internas a sentir, pensar e agir.

Portanto, todas as oportunidades vivenciadas pelos professores se somarão à sua constituição identitária. Complementando esse entendimento sobre a identidade do docente, Diniz e Fonseca (2001) explicitam que o mesmo vai se consolidando a partir das interações sociais em diferentes momentos e locais. Segundo os autores, o diploma credencia o sujeito a assumir sua profissão, portanto, esse é o primeiro passo legal, exigindo do profissional permanente reflexão e atualização. Seguindo o conceito de educação ao longo da vida. 
Assim, Machado (2012) ressalta a fragilidade na formação desse professor, que apresenta dificuldade em fomentar a prática e os princípios político-pedagógicos direcionados à EJA, apontando "os treinamentos esporádicos, os cursos aligeirados e os programas de alfabetização sem continuidade garantida, como instrumentos de desserviço à EJA". Embora os esforços da equipe da GEJA sejam em prol de auxiliar ao máximo os seus professores, não há propostas encadeadas com assuntos específicos por disciplina e a preocupação de sua interação num processo interdisciplinar. Percebe-se uma pulverização de cursos, palestras, encontros, reuniões, mas com pouco aprofundamento e direcionamento para as questões pertinentes a cada bloco do PEJA.

Segundo dados extraídos da pesquisa de Vianna e Ferreira (2015), que realizaram estudos para definir a identidade dos professores do PEJA do munícipio do RJ e a maneira pela qual chegaram até a modalidade da EJA, a composição é a seguinte: 45,94\% dos professores declaram ter identificação com os alunos da EJA e por isso escolheram trabalhar com essa modalidade de ensino.

Aparecem outras conveniências: $23,78 \%$ se mantêm por conta da adequação ao horário de outras escolas / trabalhos e/ou à necessidade de compor a jornada de trabalho na rede; $11,31 \%$ citam como motivo a complementação de renda (segunda matrícula ou "dobra"). Para alguns professores (4,48\%) esta era a função disponível para escolha, e 3,51\% dos professores afirmaram se manter na EJA por sentirem pouca identificação com crianças do ensino fundamental. Funciona, como diz a autora, como um "escape" para aqueles que não desejam exercer o magistério com crianças. Esse "escape" foi identificado na fala de vários acompanhantes de PEJA, que sinalizaram ter muitos professores sem o chamado "perfil do professor de PEJA". Seguem abaixo os dados da pesquisa.

Esse aspecto é muito importante para os gestores da GEJA, pois, mediante esse saber, se comprova que a indicação dos diretores de escolas não é a maneira mais adequada para se obter uma equipe de professores comprometidos com a modalidade da EJA. Aproximadamente a metade dos professores apontam conveniências particulares que os levaram a trabalhar no PEJA, que não a identificação com a realidade específica dos alunos desta modalidade.

Nesse campo, há uma nebulosidade grande quanto ao processo vigente para requisição pelos diretores de escolas de PEJA. Em algumas CRE é feita uma espécie de cadastro de reserva, onde os professores respondem o porquê quererem trabalhar no PEJA e quais são suas formações; assim, ocorrendo a vaga, se "recorre" a esse banco de professores, porém, na prática, esse cadastro é pró-forma, pois o que tem peso, de fato, é a indicação do diretor das escolas de PEJA. Segue um trecho da entrevista descrito por um professor acompanhante de PEJA:

"Ainda hoje há quem queira trabalhar no PEJA por saber que não terá os gritos e conflitos inerentes ao público infantil, que não terá que corrigir provas, já que a proposta do PEJA não se concentra em avaliações de provas, também por saber que sairão 
mais cedo e entrarão mais tarde, pois sabemos que os alunos chegam mais tarde por causa (..). Então, acho que precisa moralizar essa indicação feita pelos diretores de escolas. Antes havia entrevista aqui na CRE, agora é acomodação da matricula e indicação dos amigos dos amigos" (MOTA SOUZA, 2018, p. 213).

Essa discussão deve ser propícia para a quebra do paradigma da contratação dos docentes do PEJA, que na atualidade segue o processo da requisição do diretor de escola do PEJA. Nada garante que a indicação seja o melhor mecanismo de seleção, portanto, um concurso específico pode garantir, a priori, que, ao menos teoricamente, o professor esteja embasado para sua função, visto que o perfil do professor do PEJA não existe. Ele é gradativamente construído nas diversas interações do cotidiano do professor com seus alunos e, também, em todas as experiências vividas deste professor fora da realidade escolar.

Assim, acrescenta-se o entendimento de Dallepiane (2006), afirmando que, "o grande desafio contemporâneo na educação de jovens e adultos é a necessidade de educadores com formação e o compromisso social dessa formação com a diversidade de sujeitos". Ratifica-se que a proposta atual de contratação dos professores do PEJA está carregada de subjetividade e descompasso com seus princípios normativos originais, portanto, sem fundamentos regulatórios.

\section{Conclusões}

A identidade do professor (agente) tem caráter inacabado e dinâmico, visto que é um agente aprendente, que age e interage com o meio social (campo), trabalhando com as adversidades da realidade dos alunos (habitus), consolidando permanentemente suas bases identitárias à sua formação (capital cultural), em um processo de conhecimentos, baseado na concepção de aprendizagem para toda a vida, portanto, não faz sentido "acreditar" que exista um "perfil pré-estabelecido dos professores de EJA" e que este julgamento seja centrado nas decisões dos diretores das escolas de PEJA, já que a subjetividade pode se constituir de uma política clientelista entre amigos.

A sugestão procedente do campo de pesquisa aponta para o concurso público como política mais adequada para o ingresso no corpo de docente do PEJA. O concurso garante a priori embasamento teórico dos recém-contratados, que devem passar por provas objetivas e práticas e ter acompanhamento formativo no período probatório, estendendo-se por toda sua vida profissional. Quanto aos profissionais remanescentes, a indicação é que realizem cursos de pós-graduação focando na área do PEJA e que permaneçam trocando suas experiências num processo constantes de reflexão de suas práticas pedagógicas. Para tanto, a GEJA/SME/RJ precisa criar condições para que os profissionais docentes possam ter suas formações continuadas asseguradas. 
Recebido em: 10/02/2019 e aprovado em: 06/05/2019

\section{Referências}

BENICIO, Maria Luiza TAVARES. Percursos da Formação: A experiência de formação em serviço no Programa de Educação Juvenil (SME/RJ) no período 1995. Dissertação (Mestrado em Educação). $290 f$. Universidade Federal Fluminense. Niterói, RJ, 2006.

BOURDIEU, Pierre. La distinction. Paris: Les Éditions de Minuit 1979.

. Questões de sociologia. Rio de Janeiro: Marco Zero, 1983. p. 65.

Coisas ditas. São Paulo: Brasiliense. 1990.

A economia das trocas simbólicas. São Paulo: Perspectiva, 1992.

. Esboço de autoanálise. São Paulo: Companhia das Letras, 2005.

BRASIL, Lei 9394, Diretrizes e bases da educação, 1996. Estabelece as diretrizes e bases da educação nacional. Brasília, 1996.

. Lei ${ }^{\circ} \mathbf{1 1 . 7 3 8}$ de 16 de julho de 2008. Institui o piso salarial profissional nacional para os profissionais do magistério público da educação básica. Brasília, 2008.

Constituição da República Federativa do Brasil. Brasília, 1988.

BRUTTI, Elizante et al. O perfil ideal do educador em EJA: em busca da utopia possível. Revista interdisciplinar de estudo, ensino e extensão, Cruz Alta, UNICRUZ. v, 2 n. 1, p. 8. Cruz Alta - RS, 2014.

CAPUCHO, Vera. V. Educação de jovens e adultos: prática pedagógica e fortalecimento da cidadania. Cortez, 2012.

DALLEPIANE, Julieta Ida. Desafios contemporâneos na educação de jovens e adultos. Seminário Nacional Sobre Formação De Educadores De Jovens E Adultos [mesa-redonda], 23 maio 2006, Belo Horizonte.

DIAS, Clementina da Silva. A construção da cidadania no Programa de Educação Juvenil do CIEP Samuel Wainer. (Monografia) Curso de Pós-Graduação em Problemas do Desempenho Escolar. Faculdade de Humanidades Pedro II, Rio de Janeiro, 1995.

PEREIRA, Júlio Emílio Diniz; FONSECA, Maria da Conceição Ferreira Reis. Identidade docente e formação de educadores de jovens e adultos. Educação e Realidade, Porto Alegre, UFRGS, v. 26, n. 02, p.51-73, Jul./Dez, 2001.

PEREIRA, Júlio Emílio Diniz. A Construção do Campo da Pesquisa sobre Formação de Professores. Revista da FAEEBA, Porto Alegre, UFRGS, v. 27. n.53, p.54. 2018.

FÁVERO, Osmar; BRENNER, Ana Karina. Programa de Educação de Jovens e Adultos (PEJA). Anais da 29ª Reunião da Anped, GT: Educação de Jovens e Adultos, n. 18. 2006.p. 5-6.

FÁVERO, Osmar. Lições da história: os avanços de sessenta anos e a relação com as políticas de negação de direitos que alimentam as condições do analfabetismo no Brasil. In.: OLIVEIRA, I.B.; PAIVA J. (orgs.). Educação de jovens e adultos. Rio de Janeiro: DP\&A, p. 13-28, 2004. 
FRIGOTTO, Gaudêncio A. O enfoque da dialética materialista histórica na pesquisa educacional. In: FAZENDA, I. (Org.). Metodologia da pesquisa educacional. São Paulo: Cortez, 1991.

LAFFIN, Maria Hermínia LAGE FERNANDES; GAYA, Sidneya Magaly. Elementos Constitutivos no Campo da Educação de Jovens e Adultos na Formação Inicial Docente em Cursos de Pedagogia. Revista Lugares de Educação, Bananeiras, UFPA, v. 3, n. 6, p. 38-57 Jul.-Dez., 2013.

MACHADO, Abnael. Evolução do processo educacional em Rondônia. Jornal Gente de Opinião. 2012. Disponível em: http://www.gentedeopiniao.com.br/ lerConteudo. php?news=10610. Acesso em: 15 mar. 2014.

MOTA SOUZA, Carla. Políticas Educacionais de Formação Continuada e Valorização dos Docentes do Programa de Educação de Jovens e Adultos: análise das ações SME/GEJA- RJ, face ao PNE (2014-2018). Tese de Doutorado, UFF, Niterói, 2018.

NÓVOA, Antônio. Formação de professores e formação docente. In: Nóvoa, Antônio. (Org.) Os professores e sua formação. Lisboa: Dom Quixote, 1992.

Richardson, R.J. (1999). Pesquisa social: métodos e técnicas. (3a ed). São Paulo: Atlas. P. 102.

SANFELICE, José Luiz.Dialética e Pesquisa em Educação. In: LOMBARDI, J.C.; SAVIANI, D. (Orgs.). Marxismo e Educação: debates contemporâneos. 2ed. Campinas, SP: Autores, 2005.

SOARES, Flávia DOS SANTOS. Instrução pública e docência de matemática na virada do século XVIII para o XIX. Rev. Horizontes, Bragança Paulista, Universidade São Francisco, v.25, n.1, p. 9-16, 2007.

VIANNA, Cátia Maria SOUZA DE VASCONCELOS; FERREIRA, Márcia GOMES. Perfil dos professores de EJA das escolas municipais e estaduais do município do Rio de Janeiro. Revista Científica Interdisciplinar. Paranaguá, IFPR, v. 2, n. 4, p. 46. Out. /Dez. de 2015. 